\title{
Atmospheric Pressure Chemical Ionization Studies of Non-Polar Isomeric Hydrocarbons Using Ion Mobility Spectrometry and Mass Spectrometry with Different Ionization Techniques
}

\author{
H. Borsdorf \\ Department of Analytical Chemistry, UFZ Centre for Environmental Research Leipzig-Halle, Leipzig, Germany \\ E. G. Nazarov and G. A. Eiceman \\ Department of Chemistry and Biochemistry, New Mexico State University, Las Cruces, New Mexico, USA
}

\begin{abstract}
The ionization pathways were determined for sets of isomeric non-polar hydrocarbons (structural isomers, cis/trans isomers) using ion mobility spectrometry and mass spectrometry with different techniques of atmospheric pressure chemical ionization to assess the influence of structural features on ion formation. Depending on the structural features, different ions were observed using mass spectrometry. Unsaturated hydrocarbons formed mostly $[\mathrm{M}-1]^{+}$ and $\left[(\mathrm{M}-1)_{2} \mathrm{H}\right]^{+}$ions while mainly $[\mathrm{M}-3]^{+}$and $\left[(\mathrm{M}-3) \mathrm{H}_{2} \mathrm{O}\right]^{+}$ions were found for saturated cis/trans isomers using photoionization and ${ }^{63} \mathrm{Ni}$ ionization. These ionization methods and corona discharge ionization were used for ion mobility measurements of these compounds. Different ions were detected for compounds with different structural features. ${ }^{63} \mathrm{Ni}$ ionization and photoionization provide comparable ions for every set of isomers. The product ions formed can be clearly attributed to the structures identified. However, differences in relative abundance of product ions were found. Although corona discharge ionization permits the most sensitive detection of non-polar hydrocarbons, the spectra detected are complex and differ from those obtained with ${ }^{63} \mathrm{Ni}$ ionization and photoionization. (J Am Soc Mass Spectrom 2002, 13, 1078-1087) (C) 2002 American Society for Mass Spectrometry
\end{abstract}

$I^{2}$ on mobility spectrometry (IMS) permits the simple and rapid determination of volatile organic compounds by fieldable and transportable devices $[1,2]$. It is successfully used to detect warfare agents [3], explosives [4], environmental contaminations [5], narcotics and other drugs [6,7], and natural materials [8]. Other applications include process control [9] and monitoring the cabin atmosphere on board space stations [10].

The principle of IMS is based on determining the drift velocities $\left(v_{d}\right)$ attained by ionized sample molecules in the weak electric field of a drift tube at atmospheric pressure. Therefore, ions have to be formed from sample molecules to measure ion mobilities.

${ }^{63} \mathrm{Ni}$ ionization sources are commonly used in IMS for the ionization of neutral sample molecules [11, 12].

Published online August 19, 2002

Address reprint requests to Dr. H. Borsdorf, Department of Analytical Chemistry, Leipzig-Halle, Permoserstrasse 15, D-04318 Leipzig, Germany. E-mail: borsdorf@ana.ufz.de
Positive product ions are formed mainly via protontransfer reactions [13]. The relative abundances of the product ions largely depend on the gas-phase basicities of the compounds investigated as well as on the temperature and drift gas used [14, 15]. Photoionization (PI) and corona discharge (CD) ionization were developed as alternative non-radioactive ionization sources in IMS. PI enables compounds to be determined with an ionization energy below the energy emitted by the radiation source used $(10-12 \mathrm{eV})$. As known from literature, the most probable ionization pathway provides $[\mathrm{M}]^{+}$product ions [16]. Using $\mathrm{CD}$ ionization, positive product ions may be formed via different processes due to the varying strength of the electric field around the corona needle. Electron impact, photoionization and proton-transfer reactions can initiate the formation of product ions [17]. However, the formation of product ions can generally be affected by subsequent ion-molecule reactions for all the aforementioned techniques [18].

After being ionized, the ions formed are separated within the drift tube and the drift velocities are deter- 
Table 1. Substances investigated and ionization energies

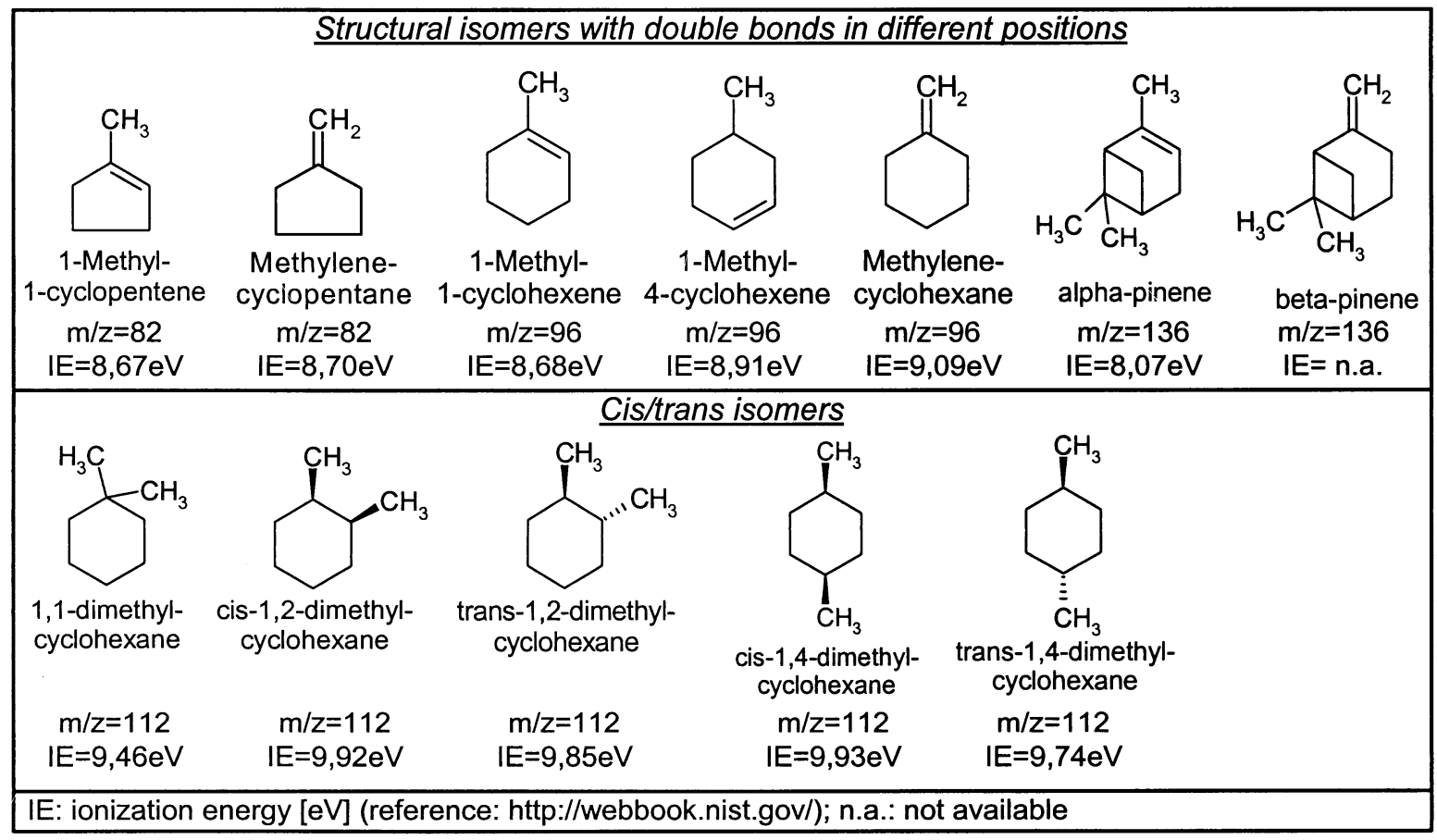

mined, which are proportional to the mobility $(\mathrm{K})$ of ions. Ion mobility is influenced by the operational parameters used as well as the mass of analytes and their collisional cross section. The collisional cross section $\left(\Omega_{\mathrm{D}}\right)$ includes structural parameters (physical size and shape) and the resultant electronic factors describing the ion-neutral interaction forces $[19,20]$. The theory of ion mobility has been extensively described elsewhere [21, 22].

The application of identical instrumentation and operational parameters (drift gas, gas flows, temperature) limits the number of variables influencing the ion mobilities of various compounds to ionic mass (m) and structure $\left(\Omega_{\mathrm{D}}\right)$. The influence of ionic mass on ion mobility can be described by mass-to-mobility correlation curves, which are known for a large number of substances. By contrast, the effect of structural differences on the ionization pathways and drift behavior is not completely understood.

Recent studies of constitutional isomeric hydrocarbons (alkylated benzenes: $\mathrm{C}_{9} \mathrm{H}_{12}$ and $\mathrm{C}_{10} \mathrm{H}_{14}$ ) have revealed that methods of atmospheric pressure chemical ionization ( ${ }^{63} \mathrm{Ni}$ and corona discharge ionization) produce differences in ion mobility spectra and in the detectable concentration ranges of isomeric compounds depending on the number and position of aliphatic side chains [23]. These differences were attributed to different ionization pathways.

Our aim was to determine what structural features affect ion formation or drift behavior in ion mobility spectrometry depending on the ionization technique used. Therefore, we investigated sets of isomeric nonpolar hydrocarbons with different structural features (saturated cis/trans isomers, unsaturated isomeric compounds with double bonds in different positions) using ${ }^{63} \mathrm{Ni}$ ionization, $\mathrm{CD}$ ionization, and PI to estimate the influence of molecular structure on the ion mobility and ionization pathways. The substances investigated and the ionization energies are summarized in Table 1 . The ionization energies of compounds are below $10 \mathrm{eV}$ and permit direct ionization using PI with the krypton lamp $(10 \mathrm{eV})$.

Investigating these isomers with identical molecular weights enables mass effects to be ruled out. Polar effects can be minimized in contrast to substances containing polar functional groups. The structure of product ions formed was analyzed by ${ }^{63} \mathrm{Ni}-\mathrm{IMS}-\mathrm{MS}$ (mass spectrometry) investigations and atmospheric pressure chemical ionization (APCI) /MS studies using photoionization.

\section{Experimental}

The substances used in this study had a purity of about 99\% and were obtained from Fluka and Sigma-Aldrich (Seelze, Germany). Their purity was verified by gaschromatography using flame-ionization detector.

\section{Ion Mobility Measurements}

The details of the sample introduction system used for ion mobility measurements and its function are described elsewhere [24]. Series of measurements with increasing concentrations were detected for each compound in order to estimate any concentration-depen- 
dence of ion mobility spectra. Liquid samples containing about $300 \mu \mathrm{l}$ of the hydrocarbons examined were sealed in permeation tubes made of polyethylene. $\mathrm{Pu}$ rified and dried ambient air was pumped through a glass column containing the permeation tube at a constant rate of $25 \mathrm{l} / \mathrm{h}$. The sample gas stream was split using flow controllers. A defined amount of the sample gas stream was rarefied with purified and dried ambient air. The flow rate of this total gas stream into the IMS was kept constant $(25 \mathrm{l} / \mathrm{h})$. The concentration of the compounds in the sample gas stream was calculated using the weight loss of the permeation vessels over a certain time. The moisture content of the gas streams was controlled by a moisture sensor AMX1 (Panametrics, Hofheim, Germany). Gas-drying by silica gel and purification by charcoal yielded a relative humidity of about $2.4 \%\left(-25{ }^{\circ} \mathrm{C}\right.$ dew point).

The measurements were performed with ion mobility spectrometers manufactured by BRUKER-SAXONIA (Leipzig, Germany) (RAID1). With the exception of ionization, all the measuring parameters were kept constant. The PI source was equipped with a krypton lamp $(10 \mathrm{eV})$. The basic features of the CD ionization source used in this study are described in detail elsewhere [17]. For $\beta$ ionization, a $555 \mathrm{MBq}{ }^{63} \mathrm{Ni}$ source was used as the electron source.

The spectrometers were equipped with a membrane inlet and operated with a bi-directional flow system. The operational parameters used to obtain the spectra were as follows: temperature of membrane inlet: $80^{\circ} \mathrm{C}$; carrier gas flow rate: $251 / \mathrm{h}$; drift gas flow rate: $25 \mathrm{l} / \mathrm{h}$; electric field: About $245 \mathrm{~V} / \mathrm{cm}$; shutter opening time: $300 \mu \mathrm{s}$; temperature of drift tube: $50^{\circ} \mathrm{C}$; pressure: Atmospheric pressure. Air was used as the carrier gas and drift gas. The reduced mobility values $\left(\mathrm{K}_{0}\right.$ values) were calculated as described in [25]. The drift times and the reduced mobility values were controlled by measuring acetone $\left(1.84 \mathrm{~cm}^{2} / \mathrm{Vs}\right)$ and di-iso-propylmethylphosphonate $\left(1.53\right.$ and $\left.1.05 \mathrm{~cm}^{2} / \mathrm{Vs}\right)$.

\section{Identification of Product Ions Using APCI-MS}

Two different techniques were used to identify the product ions formed. The photoionization source was directly used as the ion source of a API-III tandem mass spectrometer from PE-SCIEX (Toronto, Canada). A 10 eV krypton lamp was applied as the radiation source. The samples were introduced gaseously via permeation tubes as described above. The ionization source works at ambient temperature and ambient moisture. Ambient air was used as carrier gas.

To analyze product ions formed by ${ }^{63} \mathrm{Ni}$ ionization, the ion mobility spectrometry- mass spectrometer coupling was used. Coupling these techniques usually entails adjusting operational parameters of the ion mobility spectrometer because of the small sample amount which can be transferred to the mass spectrom- eter and the necessary compatibility of the electric fields between the two devices. For these reasons, the measurements were taken with a longer shutter pulse $(2.2$ ms) and a modified electric field design within a higher concentration range of compounds. Although the ion mobility spectra obtained using common spectrometers cannot be completely reproduced with this coupling, the general structures of product ions formed can still be assigned. IMS-MS couplings are currently only available using ${ }^{63} \mathrm{Ni}$ ionization.

For the coupling used, a simplified drift tube with stainless steel drift rings and Teflon insulating rings was attached to a API-III tandem mass spectrometer from PE-SCIEX. The drift tube was a conventional discrete ring design with the following specific features: Insulating rings of high-temperature stable Teflon (PTFE); press-fit seals on the Teflon rings to provide a first level of pneumatic isolation; an aluminum shell (drift tube casing) with Teflon seals to provide a second level of pneumatic isolation; access to electric utilities at an end cap; and preheated drift gas. Electron emission was effected by $370 \mathrm{MBq}$ of ${ }^{63} \mathrm{Ni}$ coated on a hollow cylinder. Ions were injected from the source region into the drift region using an ion shutter composed of a set of two grids. Ions reaching the end of the drift tube were passed through an additional distance which was a transition region for the drift tube at high temperature. With a length of $3 \mathrm{~cm}$, this region was equipped with a radiator surface and allowed the body of the IMS to be cooled. The end of this length was fitted into a Teflon socket placed into the high voltage flange of the API-III. The last ring was floated at $400 \mathrm{~V} \mathrm{DC}$ and the interface plate for the MS was $200 \mathrm{~V}$ DC enabling the facile transfer of ions to the mass spectrometer. The temperature of the drift tube and ionization region was $140{ }^{\circ} \mathrm{C}$. Air obtained from a zero air generator (Whatman, Tewksbury, MA) was used as drift gas and carrier gas.

The mass spectra were all obtained with 1.000 accumulations because of the low concentration within a mass range of 10 and $300 \mathrm{a} \mu$.

\section{Results and Discussion}

Non-polar hydrocarbons show proton affinities at or below those of hydrated protons. Therefore, the usual formation of $[\mathrm{MH}]^{+}$product ions cannot be expected. $[\mathrm{M}]^{+},[\mathrm{M}-3]^{+}$or $\left[(\mathrm{M}-3) \mathrm{H}_{2} \mathrm{O}\right]^{+}$product ions were found for non-polar alkanes in previous investigations $[26,27]$. Ion formation via subsequent isomerization including the migration of alkyl groups can be ruled out. Furthermore, comparable collisional cross sections can be expected for the sets of isomers investigated due to the minimal structural differences and the generally low dipole moments. 
Table 2. Results of mass spectrometric investigations of isomeric hydrocarbons

\begin{tabular}{|c|c|c|c|c|c|c|}
\hline \multirow[b]{2}{*}{ Substance } & \multirow[b]{2}{*}{$m / z$} & \multicolumn{2}{|c|}{${ }^{63} \mathrm{Ni}-\mathrm{IMS}-\mathrm{MS}$} & \multirow[b]{2}{*}{$m / z$} & \multicolumn{2}{|c|}{ APCI (PI)-MS } \\
\hline & & $\begin{array}{l}\text { Structure } \\
\text { supposed }\end{array}$ & $\begin{array}{c}\text { Relative } \\
\text { intensity } \\
(\%)\end{array}$ & & $\begin{array}{l}\text { Structure } \\
\text { supposed }\end{array}$ & $\begin{array}{c}\text { Relative } \\
\text { intensity } \\
(\%)\end{array}$ \\
\hline \multirow[t]{4}{*}{ Methylenecyclopentane } & 81 & {$[\mathrm{M}-1]^{+}$} & 98 & 67 & {$[\mathrm{M}-15]^{+}$} & 60 \\
\hline & 163 & {$\left[(\mathrm{M}-1){ }_{2} \mathrm{H}\right]^{+}$} & 100 & 83 & {$[\mathrm{MH}]^{+}$} & 60 \\
\hline & & & & 162 & Dimeric ion & 100 \\
\hline & & & & 245 & Trimeric ion & 60 \\
\hline \multirow[t]{4}{*}{ 1-Methyl-1-cyclopentene } & 61 & & 40 & 67 & {$[\mathrm{M}-15]^{+}$} & 45 \\
\hline & 81 & {$[\mathrm{M}-1]^{+}$} & 70 & 81 & {$[\mathrm{M}-1]^{+}$} & 100 \\
\hline & 163 & {$\left[(\mathrm{M}-1)_{2} \mathrm{H}\right]^{+}$} & 100 & 162 & Dimeric ion & 60 \\
\hline & & & & 242 & Trimeric ion & 25 \\
\hline \multirow[t]{5}{*}{ Methylenecyclohexane } & 95 & {$[\mathrm{M}-1]^{+}$} & 65 & 67 & {$\left[\mathrm{M}-\mathrm{C}_{2} \mathrm{H}_{5}\right]^{+}$} & 20 \\
\hline & 122 & & 40 & 81 & {$[\mathrm{M}-15]^{+}$} & 25 \\
\hline & 191 & {$\left[(\mathrm{M}-1)_{2} \mathrm{H}\right]^{+}$} & 100 & 96 & {$[\mathrm{M}]^{+}$} & 55 \\
\hline & 222 & & 50 & 192 & Dimeric ion & 100 \\
\hline & 285 & {$\left[(\mathrm{M}-1)_{3}\right]^{+}$} & 40 & 288 & Trimeric ion & 75 \\
\hline \multirow[t]{6}{*}{ 1-Methyl-4-cyclohexene } & 95 & {$[\mathrm{M}-1]^{+}$} & 35 & 81 & {$[\mathrm{M}-15]^{+}$} & 40 \\
\hline & 111 & {$\left[(\mathrm{M}-3) \mathrm{H}_{2} \mathrm{O}\right]^{+}$} & 65 & 95 & {$[\mathrm{M}-1]^{+}$} & 75 \\
\hline & 191 & {$\left[(\mathrm{M}-1)_{2} \mathrm{H}\right]^{+}$} & 100 & 111 & {$\left[(\mathrm{M}-3) \mathrm{H}_{2} \mathrm{O}\right]^{+}$} & 70 \\
\hline & 223 & & 30 & 136 & & 60 \\
\hline & & & & 192 & Dimeric ion & 100 \\
\hline & & & & 288 & Trimeric ion & 75 \\
\hline
\end{tabular}

\section{Ion Formation of Saturated and Unsaturated Isomeric Hydrocarbons}

Unsaturated hydrocarbons with double bonds in different positions. The mass-spectrometric measurements were performed to determine the structure of product ions formed under the conditions of APCI. The summarized results for unsaturated structural isomers are shown in Table 2. The main peaks in mass spectra obtained by ${ }^{63} \mathrm{Ni}$-IMS-MS can be attributed to monomer ions [M $1]^{+}$and dimeric ions $\left[(\mathrm{M}-1)_{2} \mathrm{H}\right]^{+}$. The dimeric ions exhibit the highest intensity in mass spectra. The abundant formation of dimeric ions is astonishing for such non-polar compounds. Additional product ions were detected for methylenecyclohexane and 1-methyl-4-cyclohexene. These ions cannot be clearly attributed to certain structures. However, they exhibit low intensity compared to monomers and dimeric ions.

Using APCI (PI)-MS, dimeric ions were mainly formed for nearly all isomers investigated. The monomers cannot be assigned to a uniform structure. Trimeric ions were also detected, as were fragment ions for all the compounds investigated. The formation of fragment ions can be assigned to the cleavage of methyl groups. However, these ions occur in a lower intensity. Differences in ion formation between the separate isomers cannot be concluded from the mass spectra obtained. Figure 1 shows the mass spectra obtained for methylenecyclopentane for example. In comparison to the mass spectra commonly detected using electron impact (EI) ionization, APCI provides a smaller amount of fragment ions.

Cis/trans isomers. As can be seen from Table 3, the ionization reactions of saturated cis/trans isomers pro- vide ions with a different structure in comparison with unsaturated compounds. Using ${ }^{63} \mathrm{Ni}$ ionization, product ions with the structure $\left[(\mathrm{M}-3) \mathrm{H}_{2} \mathrm{O}\right]$ were found as the main peak in mass spectra of nearly all cis/trans isomers. Additional peaks can be attributed to $[\mathrm{M}-3]^{+}$
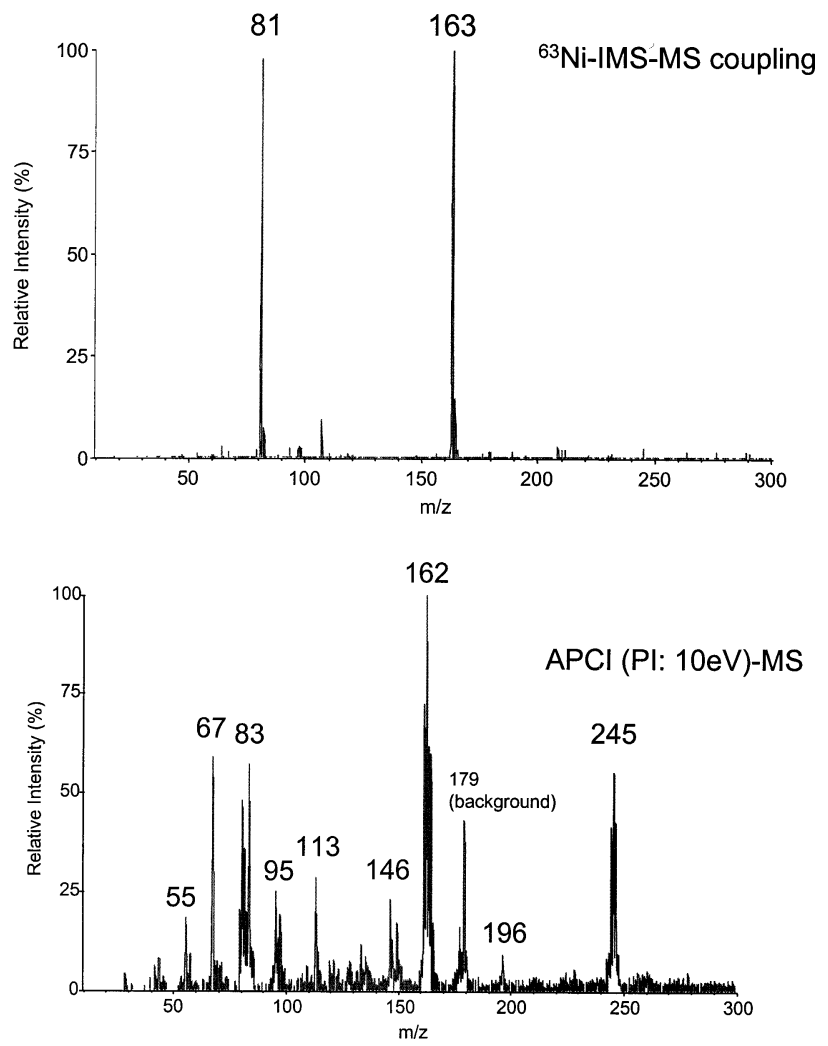

Figure 1. Product ions of methylenecylopentane obtained by APCI-MS. 
Table 3. Results of mass spectrometric investigations of cis/trans isomers

\begin{tabular}{|c|c|c|c|c|c|c|}
\hline \multirow[b]{2}{*}{ Substance } & \multirow[b]{2}{*}{$m / z$} & \multicolumn{2}{|c|}{${ }^{63} \mathrm{Ni}-\mathrm{IMS}-\mathrm{MS}$} & \multirow[b]{2}{*}{$m / z$} & \multicolumn{2}{|c|}{$\mathrm{APCl}(\mathrm{PI})-\mathrm{MS}$} \\
\hline & & $\begin{array}{l}\text { Structure } \\
\text { supposed }\end{array}$ & $\begin{array}{c}\text { Relative } \\
\text { intensity } \\
(\%)\end{array}$ & & $\begin{array}{l}\text { Structure } \\
\text { supposed }\end{array}$ & $\begin{array}{c}\text { Relative } \\
\text { intensity } \\
(\%)\end{array}$ \\
\hline \multirow[t]{3}{*}{ 1,1-Dimethylcyclohexane } & 45 & & 100 & 55 & $\mathrm{C}_{4} \mathrm{H}_{7}$-fragment & 100 \\
\hline & 57 & $\mathrm{C}_{4} \mathrm{H}_{9}$-fragment & 60 & 81 & {$\left[(\mathrm{M}-1)-\left(\mathrm{CH}_{3}\right)_{2}\right]^{+}$} & 80 \\
\hline & 71 & $\mathrm{C}_{5} \mathrm{H}_{11}$-fragment & 65 & 97 & {$[\mathrm{M}-15]^{+}$} & 100 \\
\hline \multirow[t]{7}{*}{ cis-1,1-dimethylcyclohexane } & 43 & $\mathrm{C}_{3} \mathrm{H}_{7}$-fragment & 100 & 43 & $\mathrm{C}_{3} \mathrm{H}_{7}$-fragment & 55 \\
\hline & 109 & {$[\mathrm{M}-3]^{+}$} & 45 & 55 & $\mathrm{C}_{4} \mathrm{H}_{7}$-fragment & 100 \\
\hline & 127 & {$\left[(\mathrm{M}-3) \mathrm{H}_{2} \mathrm{O}\right]^{+}$} & 80 & 69 & $\mathrm{C}_{5} \mathrm{H}_{9}$-fragment & 60 \\
\hline & & & & 83 & $\mathrm{C}_{6} \mathrm{H}_{11}$-fragment & 30 \\
\hline & & & & 97 & {$[\mathrm{M}-15]^{+}$} & 50 \\
\hline & & & & 111 & {$[\mathrm{M}-1]^{+}$} & 50 \\
\hline & & & & 127 & {$\left[(\mathrm{M}-3] \mathrm{H}_{2} \mathrm{O}\right]^{+}$} & 80 \\
\hline \multirow[t]{6}{*}{ Trans-1,2-dimethylcyclohexane } & 43 & $\mathrm{C}_{3} \mathrm{H}_{7}$-fragment & 80 & 43 & $\mathrm{C}_{3} \mathrm{H}_{7}$-fragment & 50 \\
\hline & 109 & {$[\mathrm{M}-3]^{+}$} & 35 & 55 & $\mathrm{C}_{4} \mathrm{H}_{7}$-fragment & 100 \\
\hline & 127 & {$\left[(\mathrm{M}-3) \mathrm{H}_{2} \mathrm{O}\right]^{+}$} & 100 & 69 & $\mathrm{C}_{5} \mathrm{H}_{9}$-fragment & 90 \\
\hline & & & & 97 & {$[\mathrm{M}-15]^{+}$} & 100 \\
\hline & & & & 111 & {$[\mathrm{M}-1]^{+}$} & 65 \\
\hline & & & & 127 & {$\left[(\mathrm{M}-3) \mathrm{H}_{2} \mathrm{O}\right]^{+}$} & 70 \\
\hline \multirow[t]{5}{*}{ Cis-1,4-dimethylcyclohexane } & 47 & & 50 & 55 & $\mathrm{C}_{4} \mathrm{H}_{7}$-fragment & 100 \\
\hline & 69 & $\mathrm{C}_{5} \mathrm{H}_{9}$-fragment & 45 & 69 & $\mathrm{C}_{5} \mathrm{H}_{9}$-fragment & 95 \\
\hline & 109 & {$[\mathrm{M}-3]^{+}$} & 50 & 97 & {$[\mathrm{M}-15]^{+}$} & 95 \\
\hline & 127 & {$\left[(\mathrm{M}-3) \mathrm{H}_{2} \mathrm{O}\right]^{+}$} & 100 & 111 & {$[\mathrm{M}-1]^{+}$} & 90 \\
\hline & & & & 127 & {$\left[(\mathrm{M}-3) \mathrm{H}_{2} \mathrm{O}\right]^{+}$} & 25 \\
\hline
\end{tabular}

ions and fragment ions. These results tally with previous investigations by Bell et al. [26], who found identical product ions. Deviating behavior is observed for 1,1-dimethylcyclohexane, with only fragment ions being detected for this compound.

Using PI, 1,1-dimethylcyclohexane only provides fragment ions, too. For the other saturated cis/trans isomers, fragment ions, $[\mathrm{M}-1]^{+}$ions and clustered ions with the structure $\left[(\mathrm{M}-3) \mathrm{H}_{2} \mathrm{O}\right]^{+}$were formed. The fragment ions formed are typical of hydrocarbons and comparable with those obtained using EI ionization. Dimeric ions were not observed for these substances in the concentration range considered here.

\section{Ion Mobility Measurements}

The ion mobility data (reduced mobility values and sensitivity) were compared using ion mobility measurements only. Therefore, the application of identical operational parameters (gas flow, temperatures in ionization region and drift tube) can be ensured for all the measurements.

Unsaturated hydrocarbons with double bonds in different positions. These investigations were performed to ascertain whether these compounds provide defined ion mobility spectra and whether the ions identified appear in ion mobility spectra. The results of ion mobility measurements using ${ }^{63} \mathrm{Ni}$ ionization, $\mathrm{CD}$ ionization and PI of unsaturated structural isomers are summarized in Figure 2. The reduced mobility values and the concentration ranges detected are shown. The concentrations include the range between a peak height of approximately $5 \%$ of reactant ion and the range without changes in peak area.

PI provides peaks with a sharp and symmetric profile for 1-methyl-1-cyclopentene $\left(1.53 \mathrm{~cm}^{2} / \mathrm{Vs}\right)$ and isomers of methylcyclohexene $\left(1.41 \mathrm{~cm}^{2} / \mathrm{Vs}\right)$. The double bond in these compounds is positioned inside the ring. Additional peaks with a reduced mobility value of $1.99 \mathrm{~cm}^{2} /$ Vs can be detected for the isomers of methylcyclohexene. These values are observed within the range expected for monomers of these compounds. Therefore, the main peaks of these spectra at 1.53 $\mathrm{cm}^{2} / \mathrm{Vs}$ and $1.41 \mathrm{~cm}^{2} / \mathrm{Vs}$ can evidently be attributed to the formation of dimeric ions. Figure 3 illustrates the concentration-dependence of ion mobility spectra for 1-methyl-1-cyclopentene and 1-methyl-1-cyclohexene for example. As can be seen from the series of measurements shown, no typical monomer-dimer distribution can be observed within the detectable concentration range. Therefore, the favored formation of dimeric product ions can be generally expected for the unsaturated compounds.

Contrary to these compounds, methylenecyclopentane and methylenecyclohexane provide product ion peaks of low resolution. The double bond is positioned outside the ring in these substances. Although the drift time detected is comparable to the aforementioned compounds, the peak width observed indicates the occurrence of different ions. An additional broad peak can be detected for both compounds (methylenecyclopentane: $1.24-1.19 \mathrm{~cm}^{2} / \mathrm{Vs}$; methylenecyclohexane: $\left.1.15-1.10 \mathrm{~cm}^{2} / \mathrm{Vs}\right)$. Under the conditions of IMS, trim- 


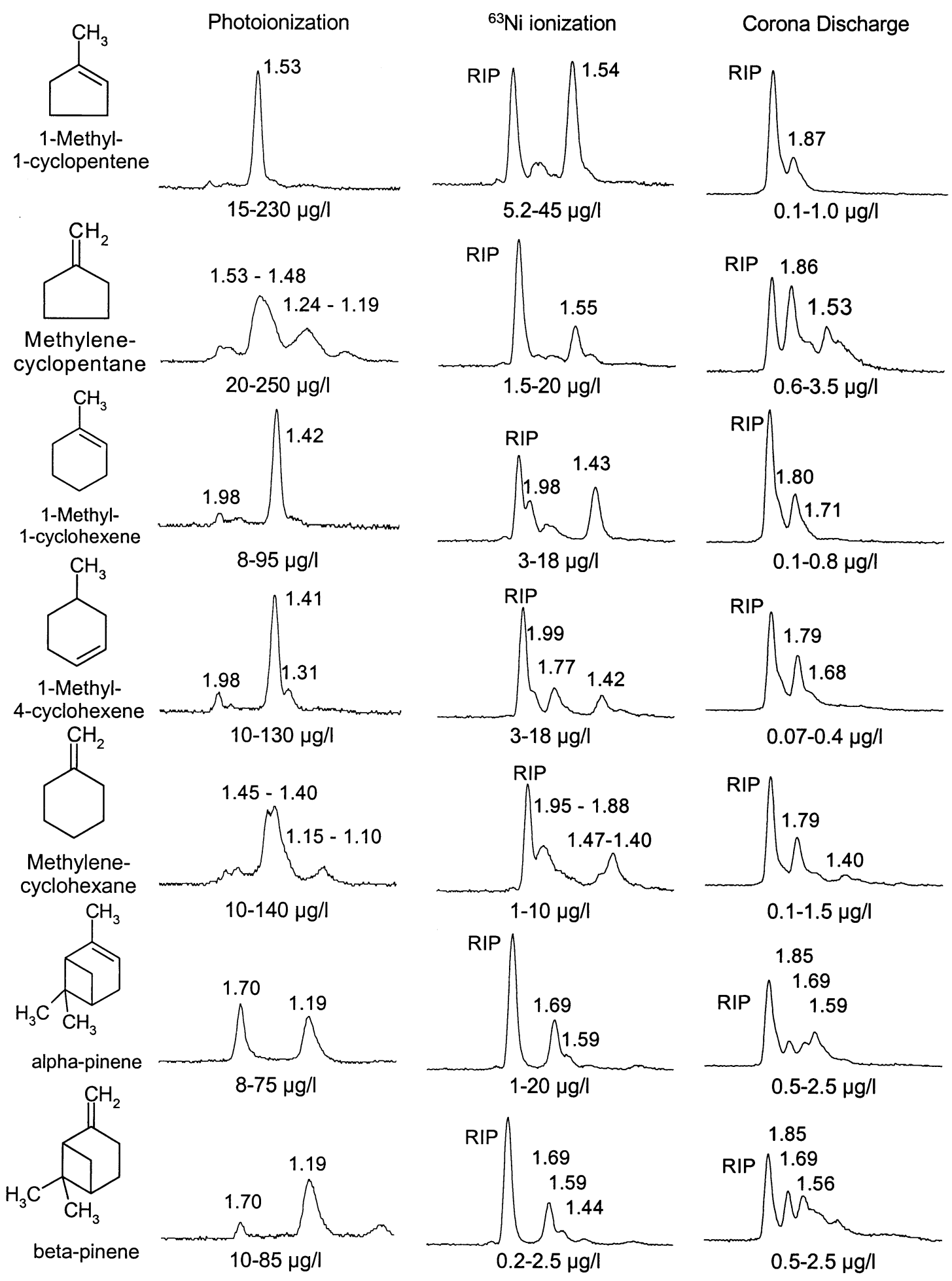

Reduced mobility values: $\mathrm{cm}^{2} \mathrm{Ns}$; RIP: positive reactant ions

Figure 2. Ion mobility spectra of structural isomers.

eric ions might be formed for these compounds which are not stable over the whole drift time and undergo fragmentation. Contrary to these substances, the two detected peaks for isomers of pinene $\left(1.70 \mathrm{~cm}^{2} / \mathrm{Vs}\right.$ and
$1.19 \mathrm{~cm}^{2} / \mathrm{Vs}$ ) can clearly be assigned to monomers and dimeric ions because of their typical intensity distribution depending on the concentration.

${ }^{63} \mathrm{Ni}$ ionization permits the more sensitive detection 

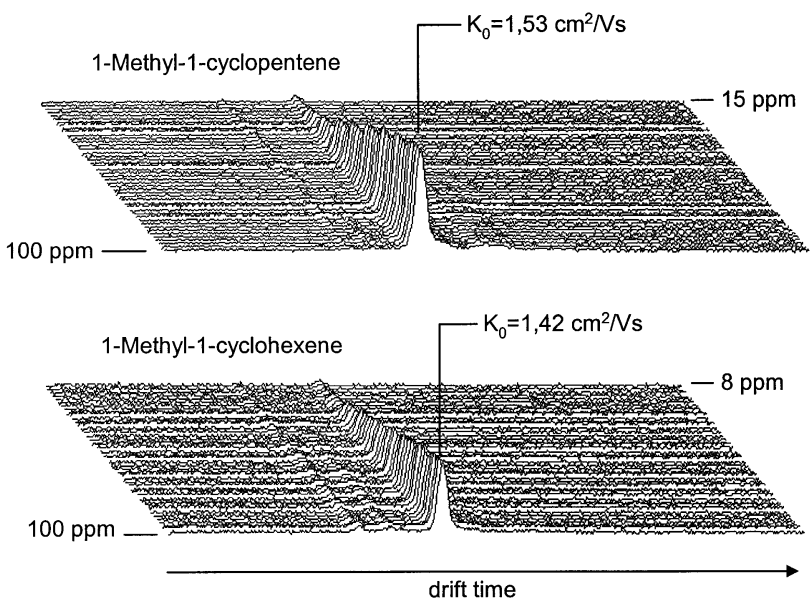

Figure 3. Concentration-dependence of ion mobility spectra.

of these compounds in comparison to PI. The product ion peaks detected exhibit similar reduced mobilities to those obtained with PI. Dimeric ions were observed for 1-methyl-1-cyclopentene $\left(1.53 \mathrm{~cm}^{2} / \mathrm{Vs}\right)$. Derivatives of methylcyclohexene provide monomers and dimeric ions. However, an elevated baseline between the reactant ion peak and the product ion peak of dimeric ions or the appearance of additional peaks indicates the decomposition of product ions formed. Only the monomers can be observed for isomers of pinene as well as additional product ions with a higher drift velocity. Therefore, the formation of additional clustered ions can be supposed.

In order to check our supposition regarding the structure of product ions formed, a mass-to-mobility correlation curve was derived according to the results of mass spectrometry $\left(1.53 \mathrm{~cm}^{2} / \mathrm{Vs}:\left[\left(\mathrm{C}_{6}-1\right)_{2} \mathrm{H}\right]^{+} ; 1.98\right.$ $\mathrm{cm}^{2} /$ Vs: $\left[C_{7}-1\right]^{+} ; 1.41 \mathrm{~cm}^{2} /$ Vs: $\left[\left(C_{7}-1\right)_{2} \mathrm{H}\right]^{+} ; 1.70$ $\mathrm{cm}^{2} /$ Vs: $\left.\left[\mathrm{C}_{10}-1\right]^{+} ; 1.19 \mathrm{~cm}^{2} / \mathrm{V}:\left[\left(\mathrm{C}_{10}-1\right)_{2} \mathrm{H}\right]^{+}\right)$. As shown in Figure 4, an excellent correlation was established between the reduced mobility values and the ionic masses supposed.

These results are confirmed by the APCI-MS measurements performed. Identical ions are evidently formed in ion mobility spectrometry $\left([\mathrm{M}-1]^{+}\right.$and $\left.\left[(\mathrm{M}-1)_{2} \mathrm{H}\right]^{+}\right)$. However, both techniques provide differences in relative abundance of product ions. Monomer ions were detected using MS while these ions were observed only with very low intensities in IMS. Obviously, these differences result from the different experimental parameters (concentration, operating pressure). Only the differences in ion formation between the separate isomers cannot be derived from mass spectra.

The use of CD ionization permits the most sensitive detection of these compounds. For the substances investigated, a correlation between the reduced mobility values calculated and the molecular weight can be observed $\left(1.86 \mathrm{~cm}^{2} / \mathrm{Vs}\right.$ for cyclic hydrocarbons with six carbon atoms, $1.79 \mathrm{~cm}^{2} / \mathrm{Vs}$ for cyclic hydrocarbons with seven carbon atoms). When comparing these reduced mobility values with those detected for monomer ions by ${ }^{63} \mathrm{Ni}$ ionization and PI, a shift of product ion peaks to higher drift velocities can be established. As these shifts indicate a higher ionic mass, the formation of clustered ions can be expected. Spectra with poor resolution are obtained for isomers of pinene consisting of three main peaks $\left(1.85,1.69,1.59 \mathrm{~cm}^{2} / \mathrm{Vs}\right)$. The peak at $1.69 \mathrm{~cm}^{2} /$ $\mathrm{cm}$ can clearly be assigned to the molecular ion. The other peaks evidently result from fragmentation and the formation of clustered ions. Although CD ionization permits sensitive detection, the peaks of compounds investigated cannot clearly be attributed to ionic structures due to the complexity of possible ionization pathways. No significant differences in the ion mobility

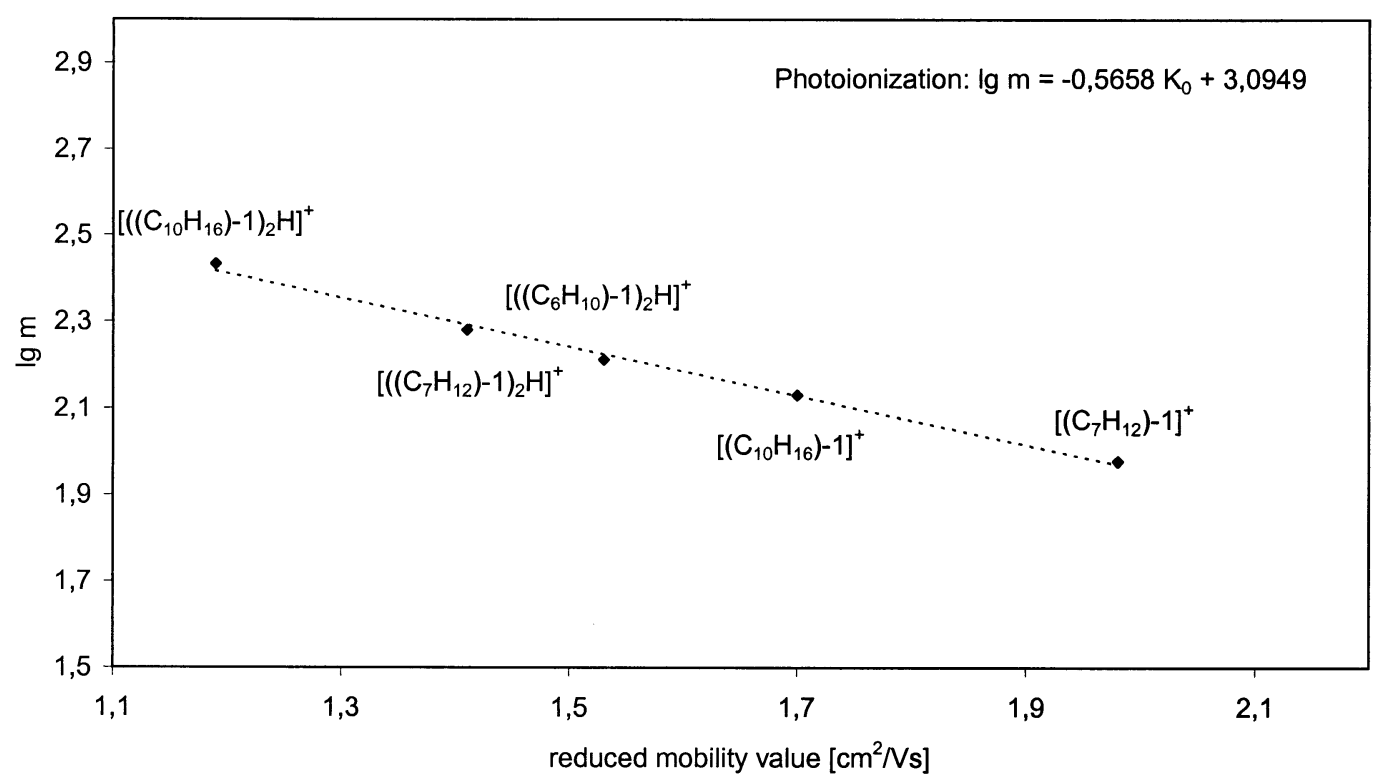

Figure 4. Mass-to-mobility correlation curve for isomeric hydrocarbons. 


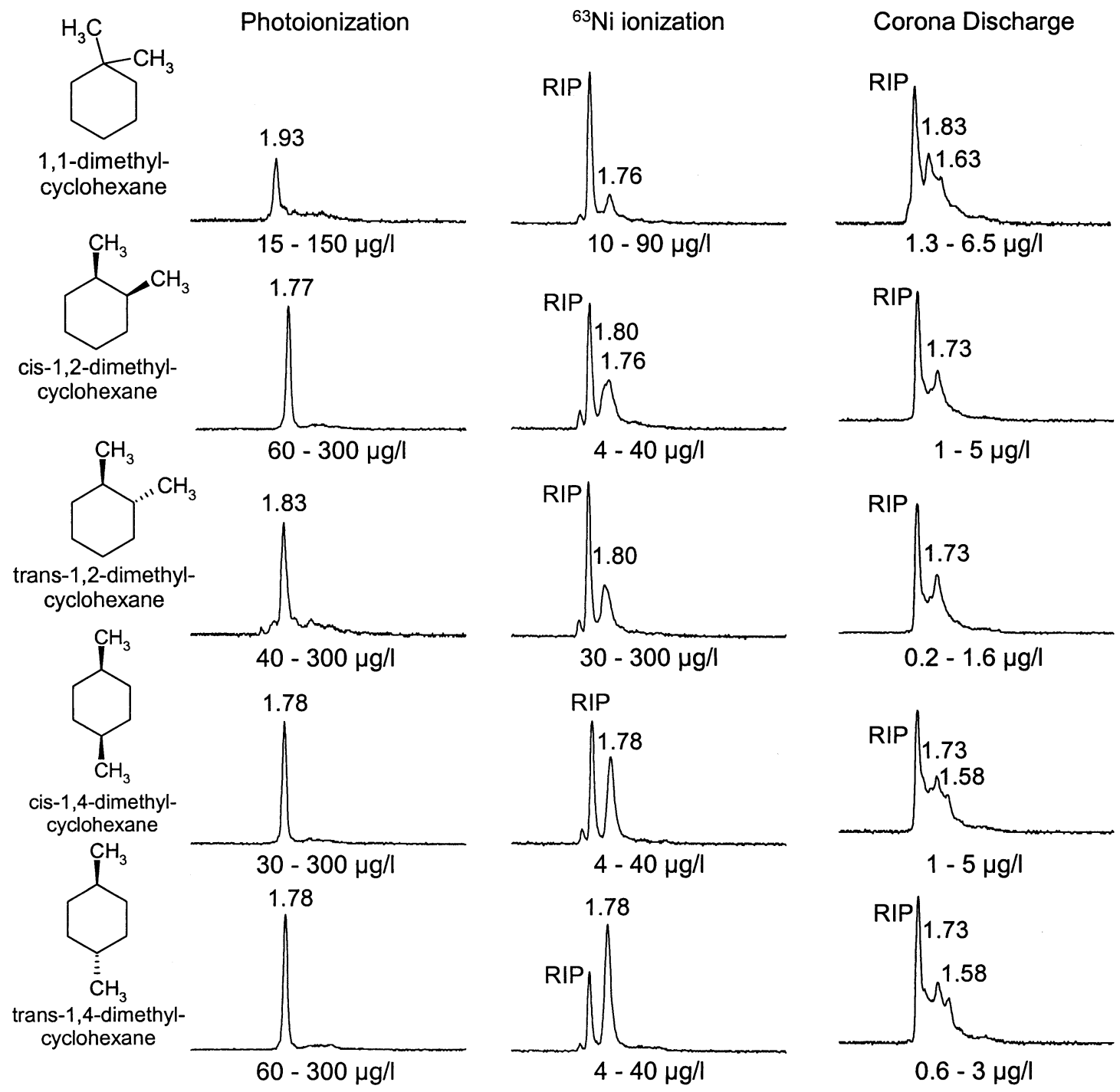

Reduced mobility values: $\mathrm{cm}^{2} \mathrm{Ns}$; RIP: positive reactant ions

Figure 5. Ion mobility spectra of cis/trans isomers.

spectra of separate isomeric compounds were established using CD ionization.

Cis/trans isomers. The results of ion mobility measurements of the cis/trans isomers investigated are summarized in Figure 5.

PI provides peaks with a sharp, symmetrical profile. Comparable reduced mobility values can be detected for cis-1,2-dimethylcyclohexane and the isomers of 1,4dimethylcyclohexane $\left(1.77 / 1.78 \mathrm{~cm}^{2} / \mathrm{Vs}\right)$. One product ion peak with a reduced mobility value of $1.83 \mathrm{~cm}^{2} / \mathrm{Vs}$ is detected for trans-1,2-dimethylcyclohexane. This shift to higher mobility values indicates a lower ionic mass of product ions formed. The application of mass-to-mobility correlation curves derived for the aforementioned compounds (Figure 4) provides for this reduced mobility value an ionic mass of $115 \mathrm{a} \mu$. Therefore, the molecular peak can be supposed. The peaks detected for the other isomers obviously result from the formation of clustered ions. According to the mass spectrometric investigations, the formation of $\left[\mathrm{M}-3\left(\mathrm{H}_{2} \mathrm{O}\right)\right]^{+}$ ions can be expected. The peak detected for 1,1-dimethylcyclohexane $\left(1.93 \mathrm{~cm}^{2} / \mathrm{Vs}\right)$ can evidently be attributed to fragments due to the elimination of methyl groups.

Although ${ }^{63} \mathrm{Ni}$ ionization permits more sensitive detection of these compounds in comparison to PI, differences in detection limits can be established. Cis1,2-dimethylcyclohexane and the isomers of 1,4-dimethylcyclohexane are most sensitively detectable. A reduced mobility value of $1.78 \mathrm{~cm}^{2} /$ Vs can be observed for isomers of 1,4-dimethylcyclohexane. Both compounds provide a sharp, symmetrical peak profile. Identical spectra are obtained for isomers of 1,2-dimethylcyclohexane. Although the product ions are detected at similar drift velocities, the broad peak (1.80-1.76 $\mathrm{cm}^{2} / \mathrm{Vs}$ ) indicate the occurrence of different ions. 1,1- 
dimethylcyclohexane provides one product ion peak $\left(1.76 \mathrm{~cm}^{2} / \mathrm{Vs}\right)$.

These results explain that the mass-to-mobility correlation curve of unsaturated compounds is not applicable to the cis/trans isomers investigated because of the formation of clustered ions with the reduced mobility value of $1.78 \mathrm{~cm}^{2} / \mathrm{Vs}$, which can be assigned to [M $\left.3\left(\mathrm{H}_{2} \mathrm{O}\right)\right]^{+}$ions. The results indicate that the ion formation is comparable to the APCI studies.

$\mathrm{CD}$ ionization permits the most sensitive detection for these compounds too. The main peaks in the ion mobility spectra of 1,2- and 1,4-dimethylcyclohexane can be observed at reduced mobility values of 1.73 $\mathrm{cm}^{2} /$ Vs. Contrary to the isomers of 1,2-dimethylcyclohexane, an additional peak can be detected as a shoulder of the main peak for isomers of 1,4-dimethylcyclohexane $\left(1.58 \mathrm{~cm}^{2} / \mathrm{Vs}\right)$. The major peak in the spectrum of 1,1-dimethylcyclohexane appears at $1.83 \mathrm{~cm}^{2} / \mathrm{Vs}$, while an additional peak appears at $1.63 \mathrm{~cm}^{2} /$ Vs. The elevated baseline between the product ion peaks and the reactant ion peak indicates the additional occurrence of fragmentations of product ions formed for all compounds. The comparison of reduced mobility values with those obtained by PI shows a shift to lower values for $C D$ ionization. Therefore, the formation of clustered ions can be supposed. However, CD ionization provides a mass-to-mobility correlation for the main peaks of nearly all the compounds investigated (1.87 $\mathrm{cm}^{2} / \mathrm{Vs}$ for $\mathrm{C}_{6}$-compounds, $1.80 \mathrm{~cm}^{2} / \mathrm{Vs}$ for $\mathrm{C}_{7}$ and $1.73 \mathrm{~cm}^{2} / \mathrm{Vs}$ for $\left.\mathrm{C}_{8}: \lg \mathrm{m}=-0.97 \mathrm{~K}_{0}+3.72\right)$. This correlation between ionic mass and reduced mobility values indicates a comparable drift behavior of product ions formed for the non-polar hydrocarbons investigated.

\section{Relationship Between Structure and Ion Formation in IMS}

General differences in ion formation were established between saturated and unsaturated hydrocarbons investigated, which can be observed in both APCI-MS and IMS. The ionization pathways provide different product ions with different stabilities.

For unsaturated compounds investigated, differences can be derived from ion mobility spectra depending on the position of double bond. Using PI, broad peaks are detected for compounds with a methylene group outside the ring while substances with the double bond inside the ring provide sharp and symmetrical peak profiles. Obviously, these differences result from the formation of different product ions with different stabilities.

However, different positions of the double bond inside the ring (1-methyl-1-cyclohexene and 1-methyl4-cyclohexene) have no influence on ion mobility spectra.

The ion mobility spectra obtained by ${ }^{63} \mathrm{Ni}$ ionization and $C D$ are weakly affected by different structural features. Using ${ }^{63} \mathrm{Ni}$ ionization, different fragment ions for the separate isomers can be observed.

PI indicates that the positions of aliphatic side chains have an influence on ionization for cis/trans isomers investigated. Fragment ions, molecular ions, or clustered ions are formed depending on the position of methyl groups. Contrary to 1,4-dimethylcyclohexane, the ion mobility spectra of 1,2-dimethylcyclohexane are affected by the configuration of methyl groups in space (cis or trans).

${ }^{63} \mathrm{Ni}$ ionization enables differences to be determined in the ion mobility spectra of 1,2- and 1,4-dimethylcylohexanes. Unlike 1,4-dimethylcyclohexane, broad peaks are detected for 1,2-dimethylcylohexanes, which indicate the occurrence of different product ions.

Using CD ionization, differences can be established depending on the position of methyl groups. Additional peaks are detected for 1,4-dimethylcyclohexane.

The spectra obtained by ${ }^{63} \mathrm{Ni}$ ionization and $\mathrm{CD}$ are not affected by the configuration of methyl groups in space (cis or trans).

\section{Conclusion}

The ion formation as well as the relative abundance of product ions depend on the structural features of compounds investigated and the ionization technique used. Saturated and unsaturated non-polar hydrocarbons provide different ions when atmospheric pressure chemical ionization is used. [(M - 1)H $]^{+}$ions and $\left[(\mathrm{M}-1)_{2} \mathrm{H}\right]^{+}$ions are mainly formed for the unsaturated structural isomers investigated. For non-polar saturated cis/trans-isomers, $[\mathrm{M}-3]^{+}$ions and [( $\mathrm{M}-$ 3) $\mathrm{H}_{2} \mathrm{O}^{+}$clustered ions can be detected. These differences are reflected in ion mobility spectra when ${ }^{63} \mathrm{Ni}$ ionization and PI are used. Both ionization techniques provide similar product ions. Using CD ionization, different product ions are formed. Although this ionization technique permits the most sensitive detection, the ionic structures of product ions cannot be clearly assigned due to the complexity of possible ionization pathways.

\section{References}

1. Lopez-Avilia, V.; Hill, H. H. Field Analytical Chemistry. Anal. Chem. 1997, 69, 289R-305R.

2. Turner, R. B.; Brokenshire, J. L. Hand-Held Ion Mobility Spectrometers. Trends Anal. Chem. 1994, 13, 275-280.

3. Sohn, H.; Steinhanses, J. Use of Ion Mobility Spectrometry for the Preliminary Evaluation of Hazardous Military Waste Sites. Int. J. Ion Mobility Spectrom. 1998, 1, 1-14.

4. Ewing, R. G.; Atkinson, D. A.; Eiceman, G. A. A Critical Review of Ion mobility Spectrometry for the Detection of Explosives and Explosive Related Compounds. Talanta 2001, 54, 515-529.

5. Borsdorf, H.; Raemmler, A.; Schulze, D.; Boadu, K. O.; Feist, B.; Weiss, H. Rapid On-Site Determination of Chlorobenzene in Water Samples Using Ion Mobility Spectrometry. Anal. Chim. Acta 2001, 440, 63-70. 
6. Keller, T.; Schneider, A.; Tutsch-Bauer, E.; Jaspers, J.; Aderjan, R.; Skopp, G. Ion Mobility Spectrometry for the Detection of Drugs in Case of Forensic and Criminalistic Relevance. Int. J. Ion Mobility Spectrom. 1999, 2, 22-34.

7. Elias, L.; Lawrence, A. H. Portable Trace Narcotics Detector for Field Use. Can. J. Spectrosc. 1987, 32, 14A-15A.

8. Snyder, A. P.; Shoff, D. B.; Eiceman, G. A.; Blyth, D. A.; Parson, J. A. Detection of Bacteria by Ion Mobility Spectrometry. Anal. Chem. 1991, 63, 526-529.

9. Baumbach, J. I.; Pilzecker, P.; Trinade, E. Monitoring of Circuit Breakers Using Ion Mobility Spectrometry to Detect $\mathrm{SF}_{6}$ decompositions. Int. J. Ion Mobility Spectrom. 1999, 2, 35-39.

10. Limero, T. Evaluation of a Flight Prototype Volatile Organic Analyzer for Monitoring Contaminants in Spacecraft Habitable Volumes. In Recent Developments in Ion Mobility Spectrometry; Baumbach, J. I.; Stach, J., Eds.; Int. Society for Ion Mobility Spectrometry: Dortmund, 1998; p 317 ISBN 3-00003676-8.

11. Hill, H. H.; Simpson, G. Capabilities and Limitations of Ion Mobility Spectrometry for Field Screening Applications. Field Anal. Chem. Technol. 1997, 1, 119-134.

12. Hill, H. H.; Siems, W. F.; Louis, R. H. St.; McMinn, D. G. Ion Mobility Spectrometry. Anal. Chem. 1990, 62, 1201A-1209A..

13. Sunner, J.; Nicol, G.; Kebarle, P. Factors Determining Relative Sensitivity of Analytes in Positive Mode Atmospheric Pressure Ionization Mass Spectrometry. Anal. Chem. 1988, 60, 1300-1307.

14. Eiceman, G. A.; Nazarov, E. G.; Rodriguez, J. E.; Bergloff, J. F. Positive Reactant Ion Chemistry for Analytical, High Temperature Ion Mobility Spectrometry: Effects of Electric Field of the Drift Tube and Moisture, Temperature, and Flow of the Drift Gas. Int. J. Ion Mobility Spectrom. 1998, 1, 28-37.

15. Karpas, Z.; Berant, Z. Effect of Drift Gas on Mobility of Ions. J. Phys. Chem. 1989, 93, 3021-3025.

16. Stach, J. Ion Mobility Spectrometry. Analytiker Taschenbuch 1997, 16, 119-154.

17. Adler, J.; Arnold, G.; Döring, H.-R.; Starrock, V.; Wülfling, E. First Results with the Bruker Corona Discharge IMS. In Recent
Developments in Ion Mobility Spectrometry; Baumbach, J. I.; Stach, J., Eds.; Int. Society for Ion Mobility Spectrometry: Dortmund, 1998; p 110 ISBN 3-00-003676-8.

18. Eiceman, G. A.; Kremer, J. H.; Snyder, A. P.; Tofferi, J. K. Quantitative Assessment of a Corona Discharge Ion Source in Atmospheric Pressure Ionization-Mass Spectrometry for Ambient Air Monitoring. Int. J. Environ. Anal. Chem. 1988, 33, 161-183.

19. Lin, S. N.; Griffin, G. W.; Horning, E. C.; Wentworth, W. E. Dependence of Polyatomic Ion Mobility on Ionic Size. J. Chem. Phys. 1974, 60, 4994-4999.

20. Karpas, Z.; Berant, Z.; Shahal, O. The Effects of Saturation and Substitution on the Mobility of Protonated Cyclic Compounds. Int. J. Mass Spectrom. Ion Processes 1990, 96, 291-297.

21. Su, T.; Bowers, M. T. Theory of Ion-Polar Molecule Collisions. J. Chem. Phys. 1973, 55, 3027-3037.

22. Sennhauser, E. S.; Armstrong, D. A. Ion Mobilities and Collision Frequencies in Gaseous $\mathrm{CH}_{3} \mathrm{Cl}, \mathrm{HCl}, \mathrm{HBr}, \mathrm{H}_{2} \mathrm{~S}, \mathrm{NO}$, and $\mathrm{SF}_{6}$ Effects of Polarity of Gas Molecules. Can. J. Chem. 1980, 58, 231-237.

23. Borsdorf, H.; Rudolph, M. Gas-Phase Ion Mobility Studies of Constitutional Isomeric Hydrocarbons Using Different Ionization Techniques. Int. J. Mass Spec. 2001, 208, 67-72.

24. Borsdorf, H.; Schelhorn, H.; Flachowsky, J.; Döring, H.-R.; Stach, J. Corona Discharge Ion Mobility Spectrometry of Aliphatic and Aromatic Hydrocarbons. Anal. Chim. Acta 2000, 403, 235-242.

25. Sprangler, G. E. Theory and Technique for Measuring Mobility Using Ion Mobility Spectrometry. Anal. Chem. 1993, 65, 3010-3014.

26. Bell, S. E.; Ewing, R. G.; Eiceman, G. A. Atmospheric Pressure Chemical Ionization of Alkanes, Alkenes, and Cycloalkanes. J. Am. Soc. Mass Spectrom. 1994, 5, 177-185.

27. Borsdorf, H.; Schelhorn, H.; Flachowsky, J.; Döring, H.-R.; Stach, J. Determinations of n-Alkanes and Branched Chain Alkanes by Corona Discharge Ion Mobility Spectrometry. Int. J. Ion Mobility Spectrom. 1999, 2, 9-14. 